white paper is indeed aiming at a moving target in trying to keep the upper end of U.K. higher education institutions competitive in income terms with even the best of the U.S. publics, let alone the top private institutions, where annual fees are already nearing $\$ 30 \mathrm{~K}$. And, indeed, there is also a trend toward the semiprivatization of state flagship campus institutions (now being called "the public Ivies"), which may push fees yet higher than the ca.\$7K per annum referred to above.

If U.K. and U.S. higher education systems continue to diverge on funding, they will then share certain features. The politics of affordability of higher education for "Middle America" during the 1990s trumped the politics of access to higher education for "Poor America," which is not surprising given the relative voting power of the two constituencies. This scenario potentially will be echoed in the United Kingdom, where in response to New Labour's white paper and its proposed $£ 3 \mathrm{~K}$ per annum tuition fee for "Middle England" the Conservative Party has focused on affordability, asserting that it would avoid the need to increase fees (or even levying them at all) by reducing the size of the higher education system and hence its accessibility to "Poor England" as a means of saving money.

The full version of this paper can be down-loaded from the OxCHEPS web-site at oxcheps.new.ox.ac.uk, "Occasional Papers."

\section{Lessons of Experience: Reform Initiatives in African Universities \\ Damtew Teferra}

Damtew Teferra is assistant research professor and editor-in-chief of the newly launched Journal of Higher Education in Africa at the Center for International Higher Education, Campion Hall, Boston College, USA. Email: teferra@bc.edu.

$\mathrm{T}$ he growing interest in revitalizing African universities has prompted the hosting of numerous regional and international conferences. The joint conference in Accra, Ghana, in September 2003-hosted by the Association of African Universities (AAU), the Association for the Development of Education in Africa-Working Group on Higher Education (ADEA-WGHE), the National Council for Tertiary Education, Ghana (NCTE), and the World Bank-was a major event that attracted numerous higher education leaders, managers, researchers, think tanks, NGOs, and funders.
Things That Work

Organized under the theme of-Improving Tertiary Education in Sub-Saharan Africa-Things that Work, the conference focused on things that work instead of dwelling on crisis talk that usually dominates such meetings. For a change, the stories we read and heard departed from the conventional tone. At times this departure felt somewhat radical. The education minister of Ghana, Elizabeth Ohene, challenged participants to consider the running of universities by business leaders. The subdued jeers that followed her remark underscore the serious challenges that underlie instituting changes in higher education institutions.

\section{Without a doubt, such forums catalyze higher education dialogues that subse- quently strengthen research in the field.}

What was in many ways comforting at the convention is the reaffirmation of commitment by the World Bank to revitalize the continent's higher education systems. Noting that the "Bank does not have a very strong credibility around higher education," Birger Fredriksen, the Bank's representative, reassured participants that the Bank "would like to strongly support higher education in Africa."

The AAU's executive secretary, Akilagpa Sawyerr, in recognition of the Bank's renewed interest, stated that the "external community rediscovered higher education in the development of the continent" and added that the Bank" has come around to recognize higher education." He reckoned that "the new direction by the Bank will change the attitude of governments in Africa."

Even though the World Bank has often been an object of much criticism surrounding higher education development in Africa, this was not the case at this event. This may be attributed to the awareness of the Bank's renewed commitment or, as someone put it," selfrestraint on the part of participants not to bite the feeding hand" that organized the conference.

A great many ideas were traded on innovations and reforms that have taken place in institutions and countries. Without a doubt, such forums catalyze higher education dialogues that subsequently strengthen research in the field, and they thus need to be organized regularly both for practitioners as well as researchers.

Many speakers presented their reform initiatives in a positive light with a cursory mention of the challenges they faced in instituting them. A complete analysis would entail digging deeper to capture the 
whole story of the reform efforts, their significance, and their impact. While one would not expect the presenters to scrutinize and criticize their own initiatives and institutions in public, one cannot help but remain curious to read the whole story of the reform campaigns.

\section{Things That May Not Work}

The conference covered a wide array of higher education issues that included funding, HIV / AIDS, management, gender, regional cooperation, and brain drain. In some cases, however, opinions were expressed that are either simply unworkable or off-the-mark, and if left unchecked, may have significant ramifications.

One stunning case was a suggestion to restrict movements of highly trained personnel to curtail brain drain (ironically made by someone who would not return to his home country). While a country may have a vested interest and may place moral and legal imperatives on its citizens, such measures are tantamount to violating their human rights. Such an approach is simply not in sync with events of the 21st century dictated by the regimes of internationalization and globalization. Furthermore, as cost sharing for higher education is gathering momentum, these legal and moral imperatives are being eroded, further complicating the issue of brain drain.

The point here is that the issues that confront us are neither simple nor straightforward and therefore call for in-depth understanding and critical analysis. While we contemplate things that work, we have to remain constantly vigilant concerning things that may not work. The renewed major initiatives need to be carefully harnessed and wisely directed-buttressed by serious and sustained research — to avoid past shortcomings.

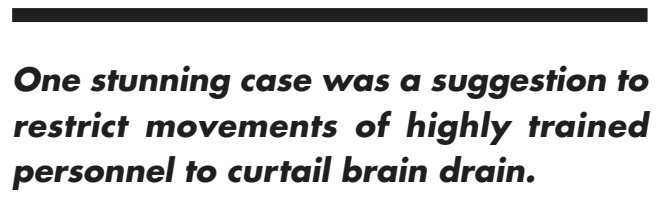

Nurturing Indigenous Knowledge

Often, change is not greeted warmly as the unknown challenges our imagination and besieges our comfort zone. As we grapple with instituting changes, there is a tremendous need to identify the maze of idiosyncrasies that are unique to individual countries, universities, institutions, and even departments. As the presentations indicated, some participants advocated a quick reform process while others advanced a gradual approach. In other cases, some advocated having a few champions of change and a top-down approach, while others supported a grassroots approach.
Exploring and developing these detailed prescriptions will entail that the community of higher education leaders engage not only champions of reform, as is often advocated, but also critics and skeptics. The notion that "who cares about skeptics when we are short of allies" would undermine elements of a "reality check."

\section{It is commendable to raise the aware- ness of higher education leaders as part of the effort to revitalize African institu- tions as this closely fits with the ongo- ing endeavors in higher education research and publishing.}

It is commendable to raise the awareness of higher education leaders as part of the effort to revitalize African institutions as this closely fits with the ongoing endeavors in higher education research and publishing. It should be cautioned, however, that simply raising the caliber of the existing leadership is far from sufficient. The training and nurturing of a new breed of higher education managers and administrators should be vigorously pursued. As the issues that confront higher education grow in complexity and magnitude, institutions need to be equipped with qualified personnel who are up to the challenge. This requires the establishment and revitalization of new programs on the continent that provide high-level training in higher education administration and management.

\section{Advocating Consortia}

Creating and maintaining good partnerships, even though not that easy, are commendable steps. The partnership between the regional and external organizations to organize the conference is praiseworthy. It is important for such interactions to continue in a more sustainable and equitable manner to play a positive role not only in revitalizing higher education systems but also building viable regional think tanks and institutions.

Sustained support of major external agencies fosters the development and influence of regional institutions. Regional institutions, such as the AAU, therefore, need to engage external agencies constructively in their effort to build a better higher education system.

The recommendations to create a consortium of universities and act through the AAU to negotiate a better Internet deal indicate aspirations for strong regional organization that could play a prominent role. There are pressing reasons to do that. Internet access, which costs under U.S.\$20 in the United States, costs as 
much as U.S.\$20,000 in Africa. Regional institutions such as the AAU need to lobby vigorously on behalf of higher education institutions by exerting pressure on governments-for instance, by demanding preferential treatment for educational and research institutions. In Senegal, for instance, telecommunications services for educational institutions cost half the regular price due largely to lobbying. The consortium initiative could be effectively extended to other activities such as acquisitions of subscriptions, books, on-line databases, and lab equipment.

Institutional Memory: Pushing the Knowledge Frontiers It is very encouraging that conferences on higher education in Africa are now commonplace. What should be religiously fostered, however, is the tracking and publication of conference papers promptly and ensuring their wide distribution. We need to capture and disseminate "institutional memory," not simply to address the challenge of "reinventing the wheel," but to push the frontiers of our knowledge of the continent's higher education system.

Selected materials from this conference will be published in the newly established journal, Journal of Higher Education in Africa. Hopefully, the participants and conference organizers will disseminate the lessons that were learned at the conference and allow the ideas to percolate up and down the line of administrative and management command in the respective countries and institutions.

\section{Caveat Emptor}

Change is a tricky matter, and its success or lack thereof is a complex handiwork of historical, social, economical, cultural, psychological, institutional, personal, and technical variables. Simply put, there is no one universal formula to effect change and innovation. While we strive to learn from things that worked, we also have to draw experience from things that simply failed although, we recognize that success and failure are not fully contagious.

As the Bank and other funding institutions reaffirm their commitment to higher education development after many years of neglect, expectations appear to be running high in Africa. It is, however, prudent to exercise caution in the face of this gathering euphoria in case the outcome does not live up to expectations. None of the stakeholders can afford a backlash for the second time round that may have severe consequences on the development of higher education on the continent.

\section{The African Virtual University- Developments and Critique Moses $\mathbf{0}$. Oketch}

Moses $O$. Oketch is research assistant professor of public policy and education, Vanderbilt University, 230 Appleton Place, Nashville, TN 37203, USA. E-mail: moses.o.oketch@vanderbilt.edu.

Tnitiatives supported by information and communicaItions technologies (ICTs) form an increasingly important component of donor-funded development projects. One such project is the African Virtual University (AVU), established by the World Bank in 1997. AVU's mission is to bridge the digital divide and knowledge gap between Africa and the rest of the world by dramatically increasing access to "global" educational resources throughout Africa. AVU reports indicate that over 27,000 African students and professionals have participated in its semester-long courses and executive business seminars since its inception in 1997. A total of 31 learning centers have been established in 17 African nations and over 3,000 hours of courses and seminars delivered, obtained from leading universities such as the Massachusetts Institute of Technology (MIT) in the United States and Curtin University in Australia. In fact, there is no doubt that ICT-based distance education seems a reasonable approach to complementing domestic capacity in African institutions in programs such as engineering, science, and management.

\section{A total of 31 learning centers have been established in 17 African nations and over 3,000 hours of courses and semi- nars delivered.}

\section{Unclear Long-Term Benefits}

In spite of the impressive numbers and the prestige attached to overseas universities, in retrospect, the World Bank and others involved in the planning of the AVU seem not to have recognized the contextual complexity of establishing a virtual university in Africa. Even more important is whether Africa is ready and in need of such a university. Consequently, AVU's long-term educational and socioeconomic potential has become unclear. Equally unclear is the intergovernmental policy framework under which the AVU should operate and even more so whether it can be regulated at all. It is not evident that those involved in the planning of AVU knew how best to use tech- 